\title{
Spatial and temporal variability of tide-induced salt flux in a partially mixed estuary
}

\author{
By \\ Patricia Ann Engel \\ B.S., University of Notre Dame, 2006 \\ Submitted in partial fulfillment of the requirements for the degree of \\ Master of Science \\ In Physical Oceanography \\ at the \\ MASSACHUSETTS INSTITUTE OF TECHNOLOGY \\ and the \\ WOODS HOLE OCEANOGRAPHIC INSTITUTION \\ September 2009 \\ (C) 2009 Patricia Ann Engel \\ All rights reserved. \\ The author hereby grants to MIT and WHOI permission to reproduce and \\ to distribute publicly paper and electronic copies of this thesis document \\ in whole or in part in any medium now known or hereafter created.
}

Signature of Author

Joint Program in Oceanography/Applied Ocean Science and Engineering Massachusetts Institute of Technology and Woods Hole Oceanographic Institution

September 16, 2009

Certified by
W. Rockwell Geyer Senior Scientist Thesis Supervisor

Accepted by

Raffaele Ferrari Chair, Joint Committee for Physical Oceanography Massachusetts Institute of Technology/ Woods Hole Oceanographic Institution 


\title{
Spatial and temporal variability of tide-induced salt flux in a partially mixed estuary
}

\author{
By Patricia Ann Engel \\ Submitted to the Woods Hole Oceanographic Institution - Massachusetts Institute of \\ Technology Joint Program in Physical Oceanography in August, 2009 in partial \\ fulfillment of the requirements for the degree of Master of Science.
}

\begin{abstract}
Mechanisms for the tidal component of salt flux in the Hudson River estuary are investigated using a 3D numerical model. Variations with river discharge, fortnightly tidal forcing, and along channel variability are explored. Four river discharge conditions were considered: $1200 \mathrm{~m}^{3} \mathrm{~s}^{-1}, 600 \mathrm{~m}^{3} \mathrm{~s}^{-1}, 300 \mathrm{~m}^{3} \mathrm{~s}^{-1}, 150 \mathrm{~m}^{3} \mathrm{~s}^{-1}$. Tide-induced residual salt flux was found to be variable along the channel, with locations of counter-gradient flux during both neap and spring tide. The magnitude of tidal salt flux scales with the river flow and has no clear dependence on the spring-neap tidal forcing. The diffusive fraction, $v$, has a value of -0.25 to 0.46 in the lower estuary, increasing to -0.23 to 1 near the head of salt. The phase lag between tidal salinity and velocity is analyzed at three cross-sections with: large positive, negative, and weak tidal salt flux. The composite Froude number, $\mathrm{G}^{2}$, is calculated along the channel and indicates nearly ubiquitous supercritical flow for maximum flood and ebb during both neap and spring tides. Subcritical flow occurs during slack water and at geographically locked locations during neap floods. Application of two-layer, frictional hydraulic theory reveals how variations in channel width and depth generate tidal asymmetries in cross-sectional salinity, the key ingredient of tidal salt flux.
\end{abstract}




\section{Acknowledgments}

This thesis has drawn upon the support and insights of many. First, thanks to my advisor, Rocky Geyer, for fueling this exploration with energy and insight. I am also grateful to John Warner (USGS) for the use of his numerical model and to Malcolm Scully (Old Dominion University) who ran the model and gave me the data to analyze. Thanks to Larry Pratt, who introduced me to hydraulics in his course and on the PhilEx exploratory cruise, where a comment from Arnold Gordon (Lamont-Doherty Earth Observatory) peaked my curiosity, and for his insightful conversations.

I am grateful to Jack Whitehead (WHOI) for his support and patience as my first year advisor. He made many great adventures possible in the GFD lab as we explored the role of mixing in a microcosm of the meridional overturning circulation. He also provided partial funding for the PhilEx cruise. I owe thanks to the PAOC student assistance fund for the rest.

Thanks to Glenn Flierl (MIT) for his continued support as my MIT based advisor and early discussions of ocean mixing papers.

A multitude of thanks is due to the other students of the Joint Program, who supported, inspired, advised and commiserated with me through classes, Generals, and my thesis. Entering PO class of 2006: Holly Dail, Rachel Horwitz, Rebecca Dell, and Cim Wortham. Official mentor: Katie Silverthorne. Unofficial mentors: Greg Gerbi, Stephanie Waterman, Melanie Fewings, Jessica Benthuysen, Beatriz Pena-Molino, Jinbo Wang, and Evgeny Logvinov. Office mates: Sophie Zhang, Tatiana Rykova. To Matt Mazloff and Yohai Kaspi who made me laugh with their antics over free food. To Kristin Pangallo for conversations at Winding Lane 512. To Joe Papp, Karin Lemkau, Andrea Burke, and others of the Joint Program entering 2006 class for friendship.

Many thanks to the education and office staff at both MIT and WHOI. In the Academic Programs Office: Marsha Gomes, Julia Westwater, Christine Charette, Valerie Caron, Jim Price, and Jim Yoder. At MIT: Mary Elliff, Roberta Allard, Jacqueline Taylor, Carol Sprague, Vicki McKenna, Beth MacEachran, Helen Dietrich, Linda Meinke, and Ronni Schwartz.

Last but not least, I am grateful for the love and support of family and friends who kept me going: Mom, Dad, Theresa, Eric Heubel, Rahul Bhattacharyya, Dave Shirokoff, Mike Matejek, Sarah Bates, Matt Ueckermann, Charlotte Siberlin, Stephanie Lovas, Jonathan Soto, CJ Hainley, Richard Clancy, Peter Grover OMV and the other OMV Oblates, Herb Yost CSC, Daniel Hennessey, the SJVSPV ladies, and Ayida Mthembu. And, in memorial of those who have finished the final race during my three years in the program: Anastasia Engel, Grace Schiltgen, Mary Fischenich, Mary Clare Fischenich. 


\section{Table of Contents}

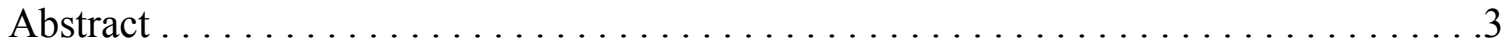

Acknowledgements ........................................

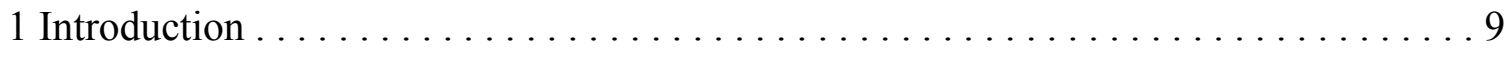

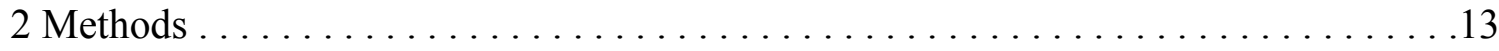

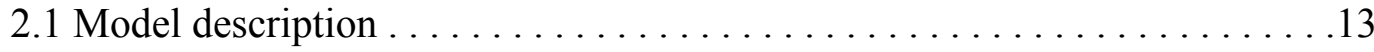

2.2 Description of Estuarine Structure . . . . . . . . . . . . . 13

2.3 Definition of Spring, Neap, Maximum Ebb and Flood ............ 16

2.4 Calculations .................................... 17

2.4.1 Salt Flux Components .......................... 17

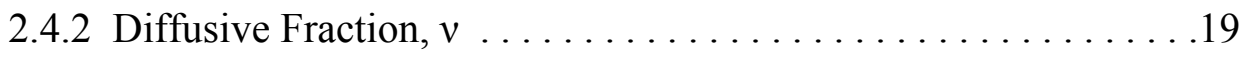

2.4.3 Tidal Dispersion Coefficient, $\mathrm{K}_{\mathrm{H}} \ldots \ldots \ldots \ldots \ldots \ldots$

2.4.4 Composite Froude number, $\mathrm{G}^{2} \ldots \ldots \ldots \ldots \ldots \ldots \ldots \ldots$

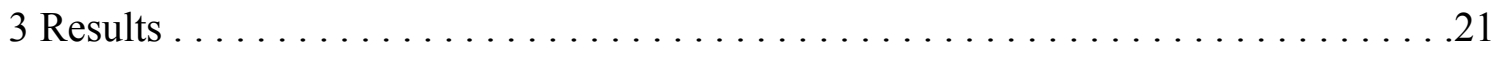

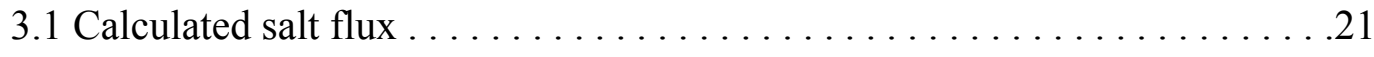

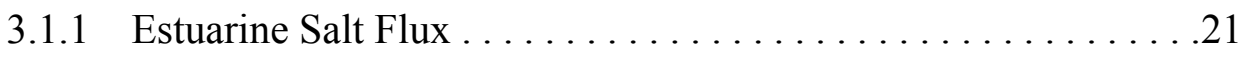

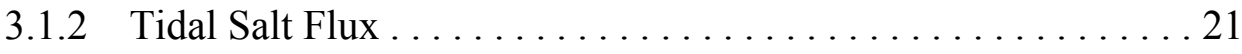

3.1.3 Diffusive Fraction, $v \ldots \ldots \ldots \ldots \ldots \ldots \ldots \ldots \ldots \ldots \ldots \ldots \ldots$ 
3.1.4 Dispersion Coefficients .................. 24

3.2 Tidal time series of Tidal Salt Flux at three locations $\ldots \ldots \ldots \ldots \ldots .25$

3.3 Temporal and Spatial Variations in Froude Number . . . . . . . . . . . 27

4 Discussion: Mechanisms of Tidal Salt Flux $\ldots \ldots \ldots \ldots \ldots \ldots \ldots \ldots \ldots$

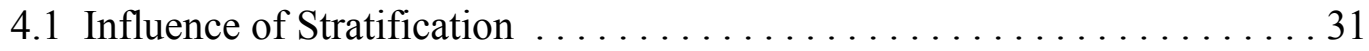

4.2 Hydraulic Adjustment of Stratification . . . . . . . . . . . . . 31

4.3 Summary and Conclusions . . . . . . . . . . . . . . . . 39

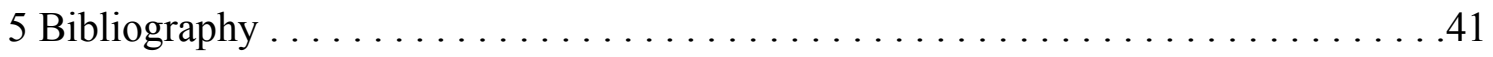

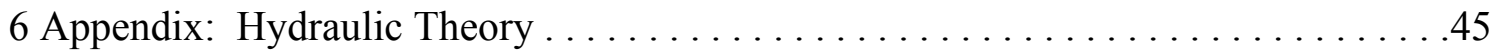




\section{Introduction}

Water quality in estuaries is often affected by the waste from nearby cities and industries. The environmental quality of coastal, urban environments depends on the dispersion of pollutants. Pollutants are transported by many of the same processes that transport salt. Thus it is important to understand salt transport.

In an estuary, the integrated content of salt is conserved at long averaging timescales. As the salt is expelled by the river flow, a collection of up-estuary fluxes replenishes it. The two main upstream fluxes are the estuarine salt flux and the tideinduced residual salt flux. The estuarine salt flux is due to the correlation of the spatial deviations of salinity and velocity. The estuarine exchange flow generates an upstream salt flux, as high salinity water flows into the estuary at depth and low salinity returns outward at the surface. The tide-induced residual salt flux, which from now on will be referred to as the tidal salt flux, is due to the correlations of temporal deviations of the salinity and velocity. Hansen and Rattray [1965] introduced a measure of the relative importance of tidal salt flux: the diffusive fraction, $v$, a ratio of the diffusive upstream salt flux to the total salt flux.

A number of observations and estimates of tidal and estuarine salt fluxes have been made. Hughes and Rattray [1980] observed a dominance of tidal salt flux in the Columbia river, with $v=0.64$ and 0.76 (for low and high discharge), and calculated analytic solutions of $v=0.59$ and 0.67 , respectively. Hunkins [1981] observed countergradient tidal salt flux (i.e., in the direction of increasing salinity) in three cross sections of the lower Hudson, with $v$ ranging from -0.36 to -0.17 . Geyer and Nepf [1996] also made cross-sectional observations in the lower Hudson, finding that tidal salt flux 
generally dominated the upstream flux under high flow conditions, but became insignificant or counter-gradient at low flow. Dronkers and van de Kreeke [1986] noticed variations in magnitude along the channel associated with changes in the crosssectional shape of the Volkerak. Bowen and Geyer [2003] observed the time dependence of tidal salt flux and estuarine salt flux (in the Hudson) and estimated typical values of $v$ $\approx 0.30$. Lerczak and Geyer [2006] extended the work of Bowen and Geyer [2003] to obtain field measurements for lateral structure, and observed fluxes corresponding to $v \approx$ 0.12. To summarize, observations and modeling estimates of tidal salt flux vary in magnitude and direction, with river flow, fortnightly tidal forcing, and at different locations along the channel. There is little consensus as to if and under what conditions the tidal salt flux dominates transport processes.

Various mechanisms for tidal salt flux have been proposed, including: shear dispersion, tidal trapping, eddies, and hydraulic response to bathymetry.

The first mechanism, shear dispersion, is the interaction of vertical or transverse velocity shears with diffusion or turbulent mixing. Shear dispersion generated by oscillatory flows was developed and explored by Bowden [1965], Okubo [1967], Smith [1982], and Zimmerman [1986]. Fisher [1972] and Smith [1976] investigated longitudinal dispersion due to lateral shears between deep channels and shallow side embayments. Ralston and Stacy [2005] discuss the importance of lateral circulation to salt flux and observed that dispersion due to vertical shear was a maximum during stratified ebbs. Larsen [1977] and Ou et al [2000] show the cross-sectional structure of shear dispersion, associating localized up-gradient tidal fluxes with bottom or side boundary layers in which the current phase leads the rest of the channel. Bowen and 
Geyer [2003] found shear dispersion responsible for three quarters of the tidal salt flux in a section of their modeled Hudson that had little along channel variation in bathymetry.

The second mechanism, tidal trapping, is the capture and delayed release of a high concentration in substance by shoreline irregularities [Schiff and Schonfield, 1953; Okubo, 1973]. The absence of side embayments in the Hudson indicates that this is not the major mechanism here.

The third mechanism, tidally trapped eddies, transports low salinity water downstream with an eddy propagating ahead of ebb tide, temporarily enhancing the phase shift of the cross-sectionally averaged salinity as the eddy passes [Fram et al, 2007]. Dispersion due to transient eddies was also numerically modeled by Awaji et al [1980] and Imasato [1983]. Chant and Wilson [1997] observed the interaction of tidally driven eddies and stratification in the Hudson.

The forth mechanism, hydraulic response of tidal flows to constrictions and sills, alters the depths of isopycnals, contributing to a phase shift in the depth-averaged salinity that may result in a net salt flux. Such a response was observed by Geyer and Nepf [1996] near a constriction in the Hudson. Two-layer Froude number estimates were made by Chant and Wilson [2000] from observations, and the hydraulic response was modeled by Stenström [2004].

This thesis work applies a high resolution numerical model to investigate tidal salt flux. The model resolves the transverse channel structure, which has been shown to be essential for quantifying the tidal salt flux [Bowen and Geyer, 2003]. This analysis addresses the along-estuary variability, which has not been previously addressed but which earlier work [e.g., Geyer and Nepf, 1996; Dronkers and van de Kreeke, 1986] 
suggests may be important due to the influence of topography on tidal salt flux. This study also explores a range of river flow conditions, which are found to influence the magnitude of tidal salt flux. Calculation methods are presented in Section 2. Section 3.1 describes the dependence of tidal salt flux on: location along the channel, fortnightly tidal forcing, and river flow conditions. Section 3.2 links the asymmetric phase lag of tidal salinity to elevated tidal salt flux. Section 3.3 quantifies the hydraulic state of the flow responsible for generating asymmetries in the tidal salinity. Section 4 discusses the important role of stratification in generating tidal salt flux and applies hydraulic theory to illustrate the impact of channel geometry on stratification. 


\section{Methods}

\subsection{Model Description}

The Regional Ocean Modeling System (ROMS) model, as configured with realistic bathymetry for the Hudson River estuary [Warner et al., 2005], was used for a set of cases with idealized forcing, similar to Scully et al. [2009]. The model was run for 45 days at constant river flows of $\mathrm{Q}=150 \mathrm{~m}^{3} \mathrm{~s}^{-1}, 300 \mathrm{~m}^{3} \mathrm{~s}^{-1}, 600 \mathrm{~m}^{3} \mathrm{~s}^{-1}$, and $1200 \mathrm{~m}^{3} \mathrm{~s}^{-1}$. The system was forced with M2 and S2 tides at the mouth so as to produce a simple fortnightly oscillation in tidal amplitude. Wind was not included. The model has 20 terrain-following, stretched sigma coordinates in the vertical and an orthogonal curvilinear 200x20 Arakawa " $\mathrm{C}$ " grid in the horizontal. Transverse grid spacing is approximately $80-110 \mathrm{~m}$. Along channel grid spacing is roughly $300 \mathrm{~m}$, from the Battery to $40 \mathrm{~km}$, then increases linearly to the Federal Dam at Troy, NY (250 km north of the Battery). The model was shown by Warner et al. [2005] to provide accurate simulations of the salinity and velocity variations in comparison with observations. Here the model is used to examine the mechanisms of salt flux in the Hudson estuary.

\subsection{Description of Estuarine Structure}

The length of the salt intrusion depends on river flow and fortnightly tidal forcing. Low river flows allow saline ocean water to extend far up the estuary. High river flows shorten the intrusion. In general, isopycnals extend further into the estuary on neap tide than on spring, however, the dependence differs for high and low flow conditions, as illustrated in Figure 2. The extent of the 2 psu and 0.1 psu isopycnals are listed in Table 1 for all river flow conditions at spring and neap tides. These upper limits are used to 
The Model Domain
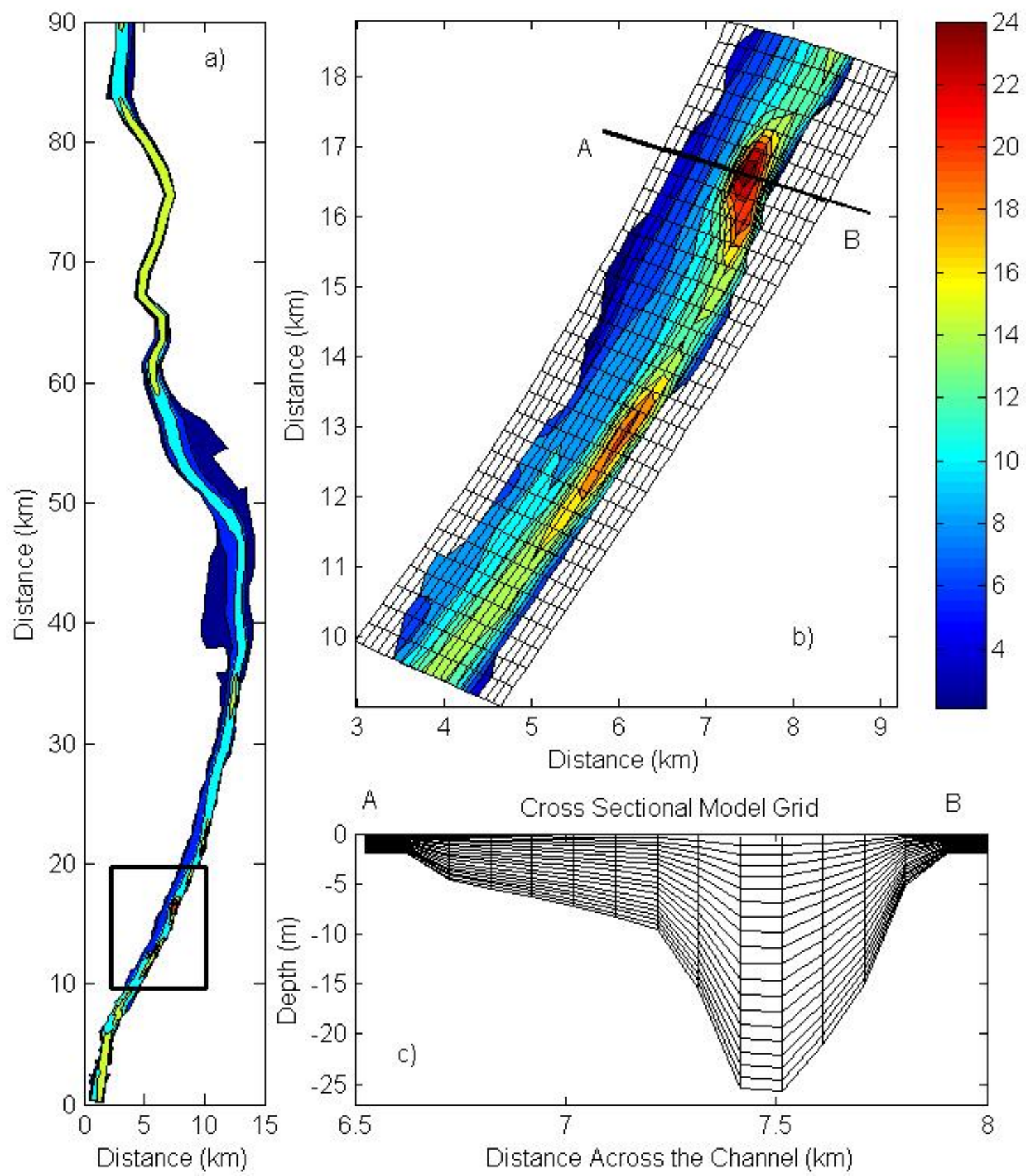

Figure 1. (a) Map of the lower model domain measured from the Battery. The boxed section is shown in (b) with the model grid. Colors depict depths in meters. A and B mark ends of the cross-section shown in (c). 
define the head of salt region as the water mass between the 2 and 0.1 psu contours. Salt flux mechanisms in this region differ from those in the lower and middle estuary, as will be demonstrated in this paper.

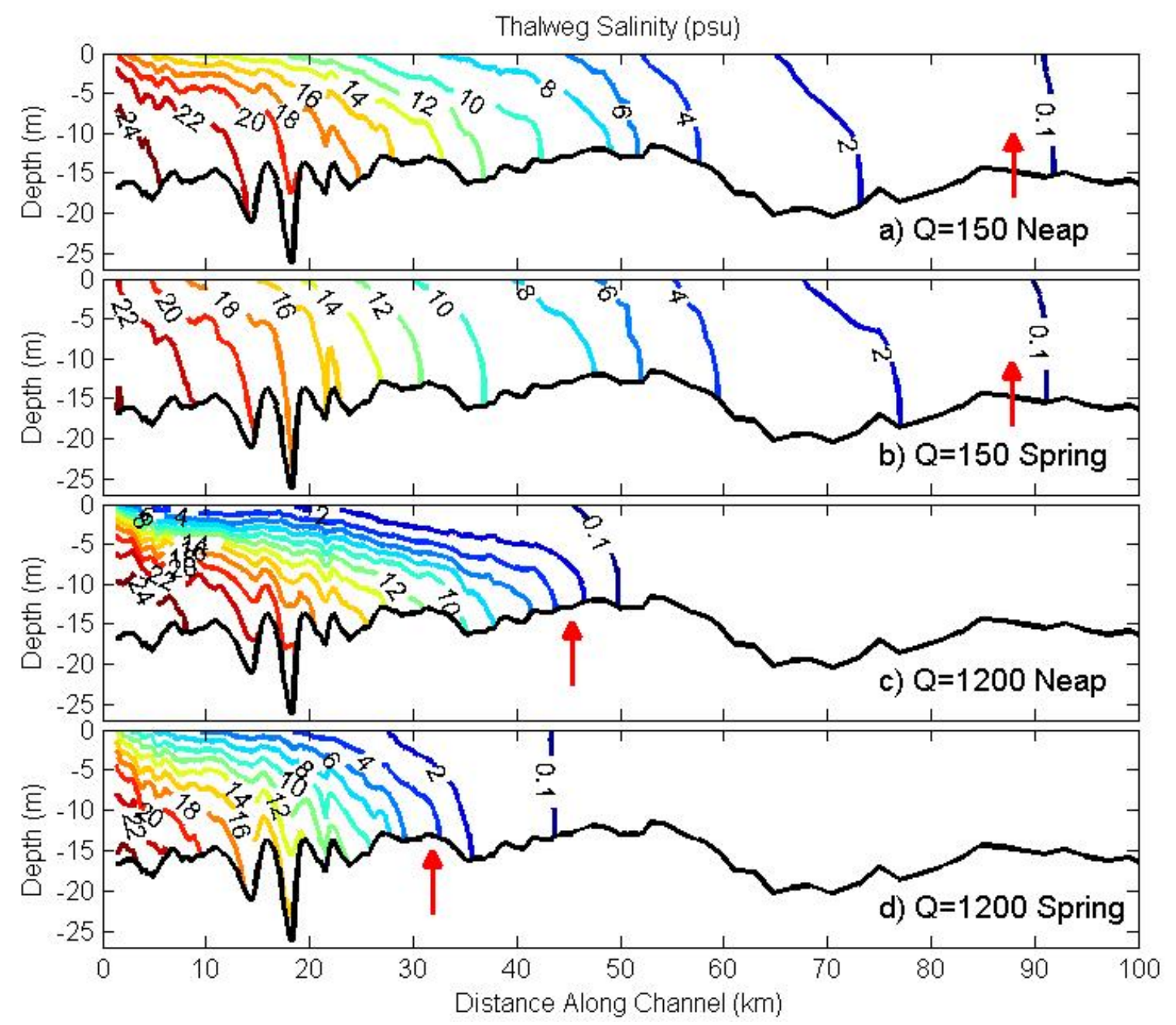

Figure 2. Thalweg salinity for low (a, b) and high (c, d) flow conditions at neap and spring tides. Red arrows mark the location at which bottom, along channel velocity remains seaward throughout the tidal cycle.

An alternative description of the edge of salt relies on the location at which the tidally averaged, along channel, bottom, thalweg velocity becomes negative (oceanward). However, the salinities at the locations of zero velocity are not consistent from spring to neap for the high river flow case. This indicates that extent of the tidally averaged, 
landward velocity is not a good indicator of the landward limit of salt. This difference is related to the landward transport of salt due to tidal salt flux as discussed below.

Table 1. Landward limit of the estuary $(\mathrm{km})$, based on different estimation methods for different discharge conditions.

\begin{tabular}{|c|c|c|c|c|c|c|c|c|}
\hline & \multicolumn{2}{|c|}{$1200 \mathrm{~m}^{3} \mathrm{~s}^{-1}$} & \multicolumn{2}{c|}{$600 \mathrm{~m}^{3} \mathrm{~s}^{-1}$} & \multicolumn{2}{c|}{$300 \mathrm{~m}^{3} \mathrm{~s}^{-1}$} & \multicolumn{2}{|c|}{$150 \mathrm{~m}^{3} \mathrm{~s}^{-1}$} \\
\hline & Spring & Neap & Spring & Neap & Spring & Neap & Spring & Neap \\
\hline $\mathrm{S}=2 \mathrm{psu}$ & 35.9 & 47.2 & 50.9 & 52.2 & 58.4 & 56.4 & 79.0 & 75.0 \\
\hline $\mathrm{S}=0.1 \mathrm{psu}$ & 44.4 & 49.9 & 59.7 & 57.5 & 75.1 & 75.1 & 92.9 & 92.9 \\
\hline $\mathrm{V}=0 \mathrm{~m} \mathrm{~s}^{-1}$ & 32.2 & 45.8 & 54.6 & 50.2 & 65.7 & 63.9 & 88.0 & 88.0 \\
\hline
\end{tabular}

\subsection{Definition of Spring, Neap, Maximum Ebb and Flood}

Spring and neap tides are defined as the times in the 45 day record at which the tidal (thalweg) velocity of a cross-section $21.4 \mathrm{~km}$ from the Battery is a maximum or a minimum. The tidal velocity was calculated as $\sqrt{2}$ times the root mean square of the bottom velocity. A parabolic fit of each deviation from the mean was used to determine an extrema in the presence of asymmetry.

Maximum ebb and flood are defined as the extrema of the cross-sectionally averaged along channel velocity at each cross-section. This time varies by 2 hours between the mouth and $80 \mathrm{~km}$. Times of maximum flood and ebb agree with times of mean integrated thalweg salinity upstream of the cross-section in question. However, the local cross-sectional averaged salinity may not be used to define maximum flood or ebb as it is modified by the processes leading to tidal salt flux. 


\subsection{Calculations}

\subsubsection{Salt Flux Components}

In this paper, the total salt flux is divided into three components in order to isolate physical mechanisms:

$$
\begin{aligned}
F_{T o t} & =<S V> \\
& =\mathrm{F}_{\mathrm{BT}}+\mathrm{F}_{\mathrm{Est}}+\mathrm{F}_{\mathrm{T}}
\end{aligned}
$$

The first term, $\mathrm{F}_{\mathrm{BT}}$, is the steady, barotropic, component associated with the net contribution of river outflow, stokes drift, and the compensating Eulerian outflow required to preserve volume. The second term, $\mathrm{F}_{\mathrm{Est}}$, is the salt flux due to the residual estuarine circulation, calculated as the product of tidally averaged deviations of salinity and along channel velocity from their respective cross-sectional mean values. The third term, $\mathrm{F}_{\mathrm{T}}$, is the tidal salt flux component, calculated as the time-dependent product of the deviations of salinity and velocity from their respective temporal means. This notation is consistent with that used by Lerczak [2006], and differs from that used by Bowen [2003] and Geyer and Nepf [1996] who decompose the last term into cross-sectionally averaged and varying components.

To calculate these three components of salt flux, the salinity and grid area, $d A$, are linearly interpolated to the grid location of along channel velocity. Then, the along channel velocity and salinity (at the velocity grid location) are decomposed into three 
components: the cross-sectionally averaged and tidally filtered, $V_{o}$ and $S_{o}$, the tidally filtered deviations from the cross-sectional mean, $V_{\text {est }}$ and $S_{\text {est }}$, and the time dependent, $V_{\text {tide }}$ and $S_{\text {tide }}$ :

$$
\begin{aligned}
& V_{o}= \frac{\langle\bar{A} \bar{V}>}{<\bar{A}>} \\
& V_{e s t}= \frac{\langle d A(V-\bar{V})>}{<d A>} \\
& V_{\text {tide }}=V-V_{o}-V_{\text {est }} \\
& S_{o}=\frac{<\bar{A} \bar{S}>}{<\bar{A}>} \\
& S_{\text {est }}=\frac{<d A(S-\bar{S})>}{<d A>} \\
& S_{\text {tide }}=S-S_{o}-S_{\text {est }}
\end{aligned}
$$

Brackets, $<>$, represent tidal filtering, and overbars represents cross-sectional averaging, a sum weighted by the area of each grid cell, $d A$. The barotropic flux is calculated as the filtered product of $V_{o}$ and $S_{o}$, multiplied by the area of the cross-section:

$$
F_{B T}=<\bar{A}><V_{o} S_{o}>
$$

The estuarine salt flux is calculated as the cross-sectional average of the product of the estuarine velocity and salinity, $V_{e s t}$ and $S_{\text {est }}$ :

$$
F_{E s t}=<\bar{A}><\overline{V_{e s t} S_{e s t}}>
$$

The tidal salt flux is calculated as the tidally filtered product of the cross-sectional area and the cross-sectional average of the time dependent salinity and velocity, $V_{\text {tide }}$ and $S_{\text {tide }}$ :

$$
F_{T}=<\overline{V_{\text {tide }} S_{\text {tide }}} \bar{A}>
$$




\subsubsection{Diffusive Fraction, $v$}

The diffusive fraction, $v$, is based on Hansen and Rattray [1965, 1966], but is modified to allow for time-dependence in the salt balance. The modified definition provides the ratio of the tidal salt flux to the sum of the magnitudes of estuarine and tidal fluxes:

$$
v=\frac{F_{T}}{\left|F_{T}\right|+\left|F_{E s t}\right|}
$$

This $v$ is modified from the original definition of Hansen and Rattray in order to allow for time-varying salt content in the estuary. The sum of tidal salt flux and estuarine salt flux is not assumed to balance the barotropic outflow. Instead, the sum of the magnitudes of estuarine and tidal salt flux is used as a measure of the total salt transport. For steadystate regimes, with zero or up-estuary tidal salt flux, the value of $v$ is the same as in Hansen and Rattray. However, this modification provides a robust definition in a broader set of circumstances.

\subsubsection{Tidal Dispersion Coefficient, $K_{H}$}

The coefficient of dispersion for each component is calculated as the quotient of the flux and the local along channel salinity gradient:

$$
K_{T}=\frac{F_{T}}{<\frac{d s}{d y}>}, \quad K_{E s t}=\frac{F_{E s t}}{<\frac{d s}{d y}>}
$$

A coarse geometric average was employed to obtain a meaningful estimates of tidal and estuarine dispersion. The geometric average divided the estuary into three regions: the lower estuary $(\mathrm{y}<35 \mathrm{~km})$, the upper estuary $(35 \mathrm{~km}-2$ psu limit), and the head of salt ( 2 
psu-0.1 psu limits). Spatial averages were taken before the quotient in order to avoid amplifying noise.

\subsubsection{Composite Froude number, $G^{2}$}

In order to characterize the hydraulic state of the flow, two-layer, frictional theory is applied. Each cross-section was divided into two layers. The upper layer $(\mathrm{i}=1)$ is comprised of all grid cells in which the salinity was less than the mean of the minimum and maximum salinities in the thalweg water column. The rest of the grid cells form the lower layer $(\mathrm{i}=2)$. Layer salinities and velocities, $s_{i}$ and $v_{i}$, are calculated by means of a weighted average, in which the weighting is the cross-sectional area of the grid cell, $d A$ :

$$
s_{i}=\frac{\int_{i} s d A}{A_{i}}, \quad v_{i}=\frac{\int_{i} v d A}{A_{i}}, \quad g^{\prime}=g \beta\left(s_{2}-s_{1}\right)
$$

The reduced gravity, g', is calculated from the layer salinities using the constants:

$\beta=0.78 \times 10^{-3} \mathrm{psu}^{-1}$ (Eq. 13 ). The upper layer thickness, $h_{l}$, was defined as the depth of the deepest grid cell of layer 1 over the thalweg. The lower layer thickness, $h_{2}$, is the difference between the upper layer thickness and the total thalweg depth. These instantaneous quantities are used to calculate the layer and composite Froude numbers, $F_{1}^{2}, F_{2}{ }^{2}$, and $G^{2}$, [Stommel and Farmer, 1952]:

$$
\begin{aligned}
& F_{1}^{2}=\frac{v_{1}^{2}}{g^{\prime} h_{1}} \\
& F_{2}^{2}=\frac{v_{2}^{2}}{g^{\prime} h_{2}} \\
& G^{2}=F_{1}^{2}+F_{2}^{2}
\end{aligned}
$$




\section{Results}

\subsection{Calculated salt flux:}

\subsubsection{Estuarine Salt Flux}

The magnitudes of the calculated estuarine salt flux agree with those found in observations [Lerczak, 2006; Bowen and Geyer, 2003; Geyer and Nepf, 1996]. The estuarine salt flux is upstream everywhere along the channel, generally decreasing in magnitude with distance from the mouth (Fig. 3a,b). Local geometry leads to variation from this trend. The magnitude diminishes from high to low river flows, in agreement with field observations [Bowen and Geyer, 2003] and theoretical studies [Hansen and Rattray, 1966]. Spring estuarine salt fluxes are reduced from neap values by a factor of 3 (calculated from the ratio of neap to spring means of fluxes oceanward of $45 \mathrm{~km}$ ). No consistent trend with river flow is apparent in this reduction factor. Thus, the magnitude of model estuarine salt flux agrees with observed field values, decreases along the channel with localized variations, increases from spring to neap, scales with river flow, and always acts as a down-gradient flux.

\subsubsection{Tidal Salt Flux}

Magnitudes of the spatially averaged calculated tidal salt flux are consistent with observations [Lerczak, 2006]. Tidal salt flux has a positive mean indicative of generally 

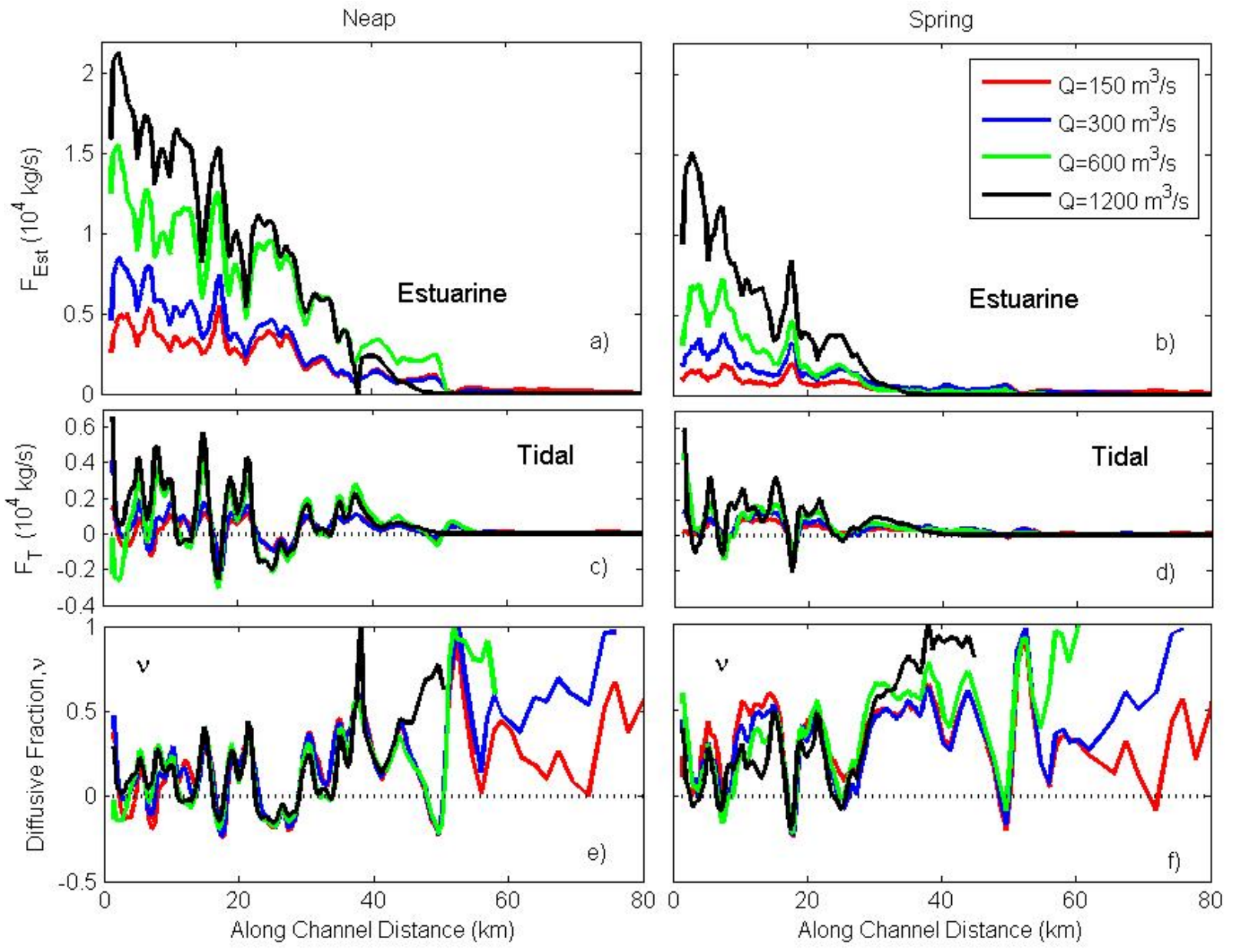

Figure 3. Along channel estuarine salt flux at neap (a) and spring (b). Along channel tidal salt flux at neap (c) and spring (d). Along channel diffusive fraction, $v$, at neap (e) and spring (f).

upstream flux throughout the whole estuary (Fig. 3c,d), with magnitudes that scale with river flow. Although the spatially averaged tidal salt flux is down-gradient (landward), temporally persistent, localized, strongly counter-gradient fluxes are observed. Such along channel variability has been seen in field observations of individual cross-sections by Hunkins [1981], Lewis and Lewis [1983], and Geyer and Nepf [1996]. 
Tidal salt flux does not have a clear spring-neap dependence, consistent with the findings of Bowen and Geyer [2003] and Lerczak [2006]. However, the amplitude of localized variations of tidal salt fluxes appears enhanced at neap tide (Fig. 3c, d).

\subsubsection{Diffusive Fraction, $v$}

The diffusive fraction, $v$, has a positive spatial mean, localized negative zones, and a tendency to increase near the head of salt (Fig. 3e,f). The along channel (mouth to the 0.1 psu limit) means of $v$ range $0.12-0.18$ at neap and $0.30-0.35$ at spring (Table 2). Two trends with river flow are apparent during spring tide. In the lower estuary, $v$ is largest for smaller river flows. In contrast, in the upper estuary, $v$ becomes greatest for larger river flows. From neap to spring, $v$ increases by roughly a factor of 2 . This is mainly a result of the large decrease in magnitude of the estuarine salt flux from neap to spring; in fact, the tidal salt flux generally decreases during spring tides (Fig. 3), but not as much as the estuarine salt flux.

Table 2. Along channel means of $v$ at neap and spring tide.

\begin{tabular}{|c|c|c|c|c|}
\hline & $\frac{1200 \mathrm{~m}^{3} \mathrm{~s}^{-1}}{}$ & $\underline{600 \mathrm{~m}^{3} \mathrm{~s}^{-1}}$ & $\underline{300 \mathrm{~m}^{3} \mathrm{~s}^{-1}}$ & $\underline{150 \mathrm{~m}^{3} \mathrm{~s}^{-1}}$ \\
\hline Neap & 0.13 & 0.12 & 0.18 & 0.16 \\
\hline Spring & 0.30 & 0.35 & 0.31 & 0.33 \\
\hline
\end{tabular}




\subsubsection{Dispersion Coefficients}

Because of the large amount of spatial variability of the tidal salt flux, a meaningful estimate of a dispersion coefficient required spatial averaging of the salt flux and salinity gradient. Average values were computed for the lower $(5-35 \mathrm{~km})$ and upper $(35 \mathrm{~km}-2 \mathrm{psu})$ estuary, which differ both in their salinity structure and geometry.

In the lower estuary, estuarine dispersion coefficients ranged from $150-2500 \mathrm{~m}^{2} \mathrm{~s}^{-1}$, and tidal dispersion coefficients fell in the range of $30-280 \mathrm{~m}^{2} \mathrm{~s}^{-1}$. Both coefficients were reduced in the upper estuary with respective ranges of $0-300 \mathrm{~m}^{2} \mathrm{~s}^{-1}$ and $15-100 \mathrm{~m}^{2} \mathrm{~s}^{-1}$ (Fig. 4). Both estuarine and tidal dispersion coefficients increase in magnitude under
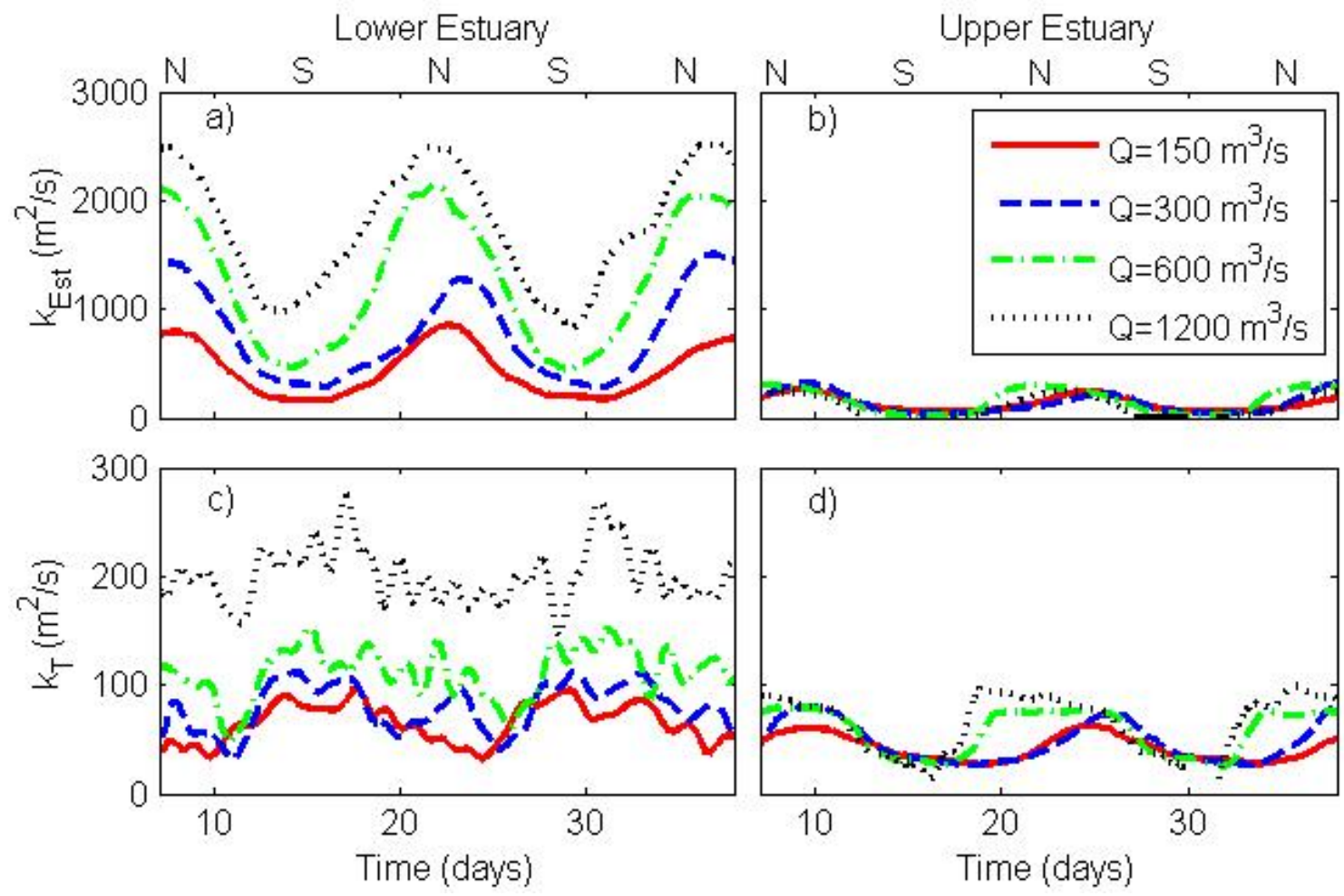

Figure 4. Time series of regional averages of the estuarine dispersion coefficient, $\mathrm{K}_{\mathrm{Est}}$, in the (a) lower estuary and (b) upper estuary. Time series of regional averages of the tidal dispersion coefficient, $\mathrm{K}_{\mathrm{T}}$, in the (c) lower estuary and (d) upper estuary. Spring and neap are marked by S and $\mathrm{N}$ at the top. 
higher river flow conditions. $\mathrm{Q}=1200 \mathrm{~m}^{3} \mathrm{~s}^{-1}$ in the upper estuary is an exception to this as the estuarine salt flux disappears at spring tide when the head of salt reaches the $35 \mathrm{~km}$ averaging boundary (Table 1). The estuarine dispersion coefficient maintains the same spring-neap variation in both regions (large during neap with a phase lag dependent on the magnitude of the river flow). In contrast, the tidal dispersion coefficient variation with fortnightly forcing is different between the lower and upper estuary. While there is a clear spring-neap cycle in the upper estuary (large during neap), there is only a hint of such in the lower channel, possibly the reverse for low river flows.

\subsection{A detailed look at Tidal Salt Flux at three locations}

In order to investigate the mechanisms of tidal salt flux, three cross-sections were studied. These cross-sections were studied during neap tide, when the tidal salt flux is largest. The $\mathrm{Q}=600 \mathrm{~m}^{3} \mathrm{~s}^{-1}$ case was used as an intermediate flow condition for the Hudson. The three locations studied are examples of locations with i) large, positive tidal salt flux $(14.8 \mathrm{~km})$, ii) large, negative tidal salt flux $(17.1 \mathrm{~km})$, and iii) weak tidal salt flux $(32.7 \mathrm{~km})$, shown in figure 5 .

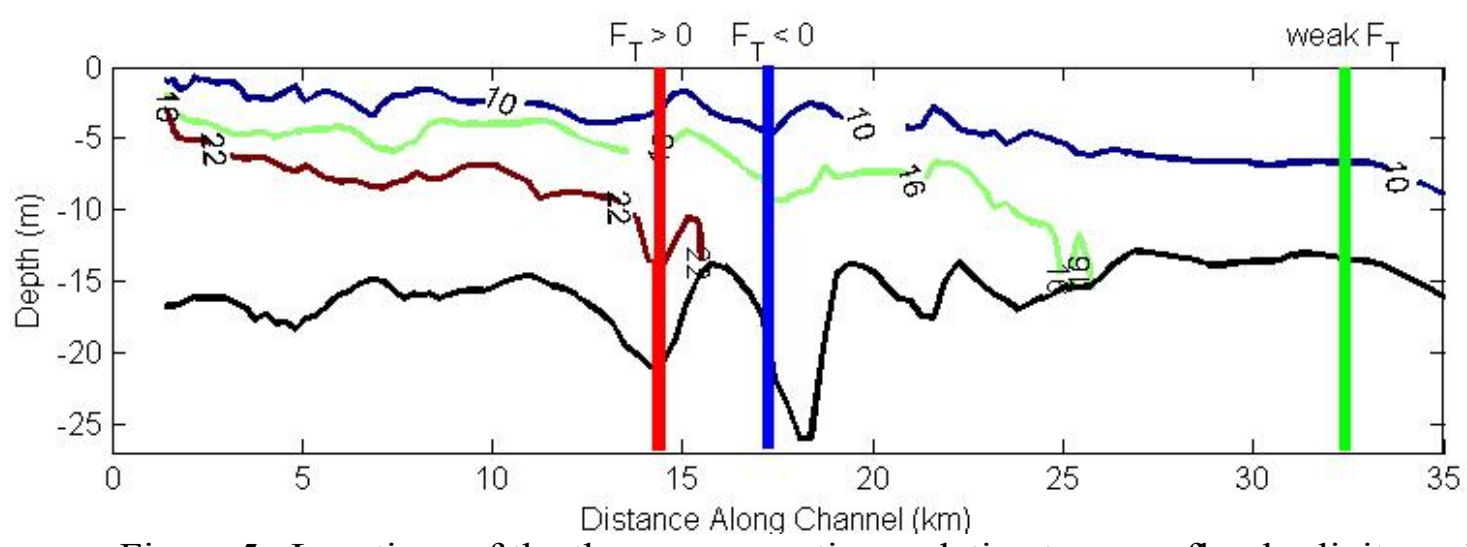

Figure 5. Locations of the three cross sections relative to neap, flood salinity and thalweg depth. 
The time series through a single tidal cycle of cross-sectionally averaged along channel velocity and salinity reveal that asymmetric salinity anomalies are the key to generating tidal salt flux (Fig. 6a,b). While nearly in quadrature at maximum ebb, the tidal deviations in salinity and velocity are out of quadrature at maximum flood. At the location of positive tidal salt flux, the flood salinity reaches its mean value before the velocity reaches its maximum. At the location of weak tidal salt flux, the flood salinity reaches its mean at the same time as the velocity peaks (i.e., it remains in quadrature), and at the location of negative tidal salt flux, the salinity is lagged relative to velocity (Fig. 6b). Calculated phase differences are respectively 63.7, 91.0, and 109.0 degrees (M2 tidal component). Thus, the tidal salinity cycle was found to lead quadrature with the velocity cycle at locations of positive tidal salt flux, match quadrature for weak tidal salt flux, and lag quadrature for negative tidal salt flux, at maximum flood, while remaining consistently in quadrature at maximum ebb.

The in-phase part of the velocity and salinity fluctuations (i.e., the shift out of quadrature) determines the magnitude of the tidal salt flux. The advancing phase of salinity produces positive salt flux, and retarded phase leads to negative salt flux. The product of cross-sectionally averaged tidal deviations (Fig. 6c) provides the majority of the tidal salt flux, though the contribution of the cross-sectionally varying component is non-negligible.

Many processes influence the cross-sectional averaged salinity. The redistribution of salt within a cross-section cannot, by itself, affect the cross-setional average salinity. Instead, a process which moves salt into and out of the plane is required. Geyer and Nepf [1996] proposed that a hydraulic response to channel geometry 
distorts the salinity structure generating tidal salt flux. The following section quantifies this hydraulic response.

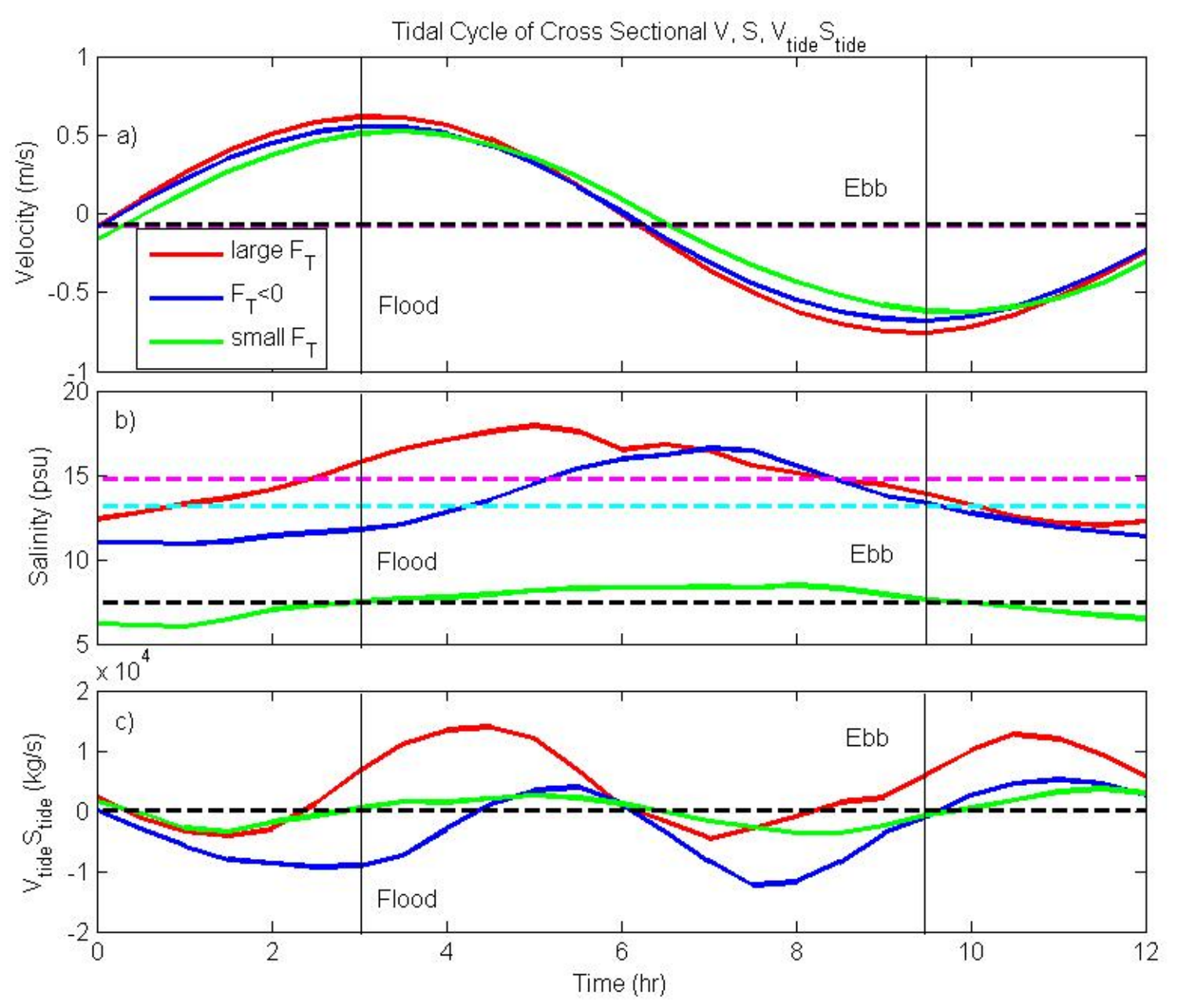

Figure 6. Tidal time series of cross sectional (a) along channel velocity, (b) salinity, (c) $\mathrm{V}_{\text {tide }} \mathrm{S}_{\text {tide }}$ at locations of large, negative, and small tidal flux. Mean salinities are indicated with dashed lines in $b$. Vertical lines at hours 3 and 9.5 mark maximum flood and ebb.

\subsection{Temporal and Spatial Variations in Froude Number}

The flow was found to be supercritical, $G^{2}>0$, throughout much of the channel at both maximum flood and ebb during spring and neap tides. During spring tide, the flow 
was supercritical everywhere due to the weaker stratification (low reduced gravity) and high velocities which elevate Froude numbers. During neap ebb tide, the flow was supercritical everywhere. During neap flood tide, supercritical flow was prevalent under low river flow conditions, whereas subcritical flow was common for high river flow conditions. In all cases, the flow was subcritical just preceding and following slack water. Zones of exceptionally high and low Froude numbers were found to be geographically locked for several hours before and after maximum flood (Fig 7a).

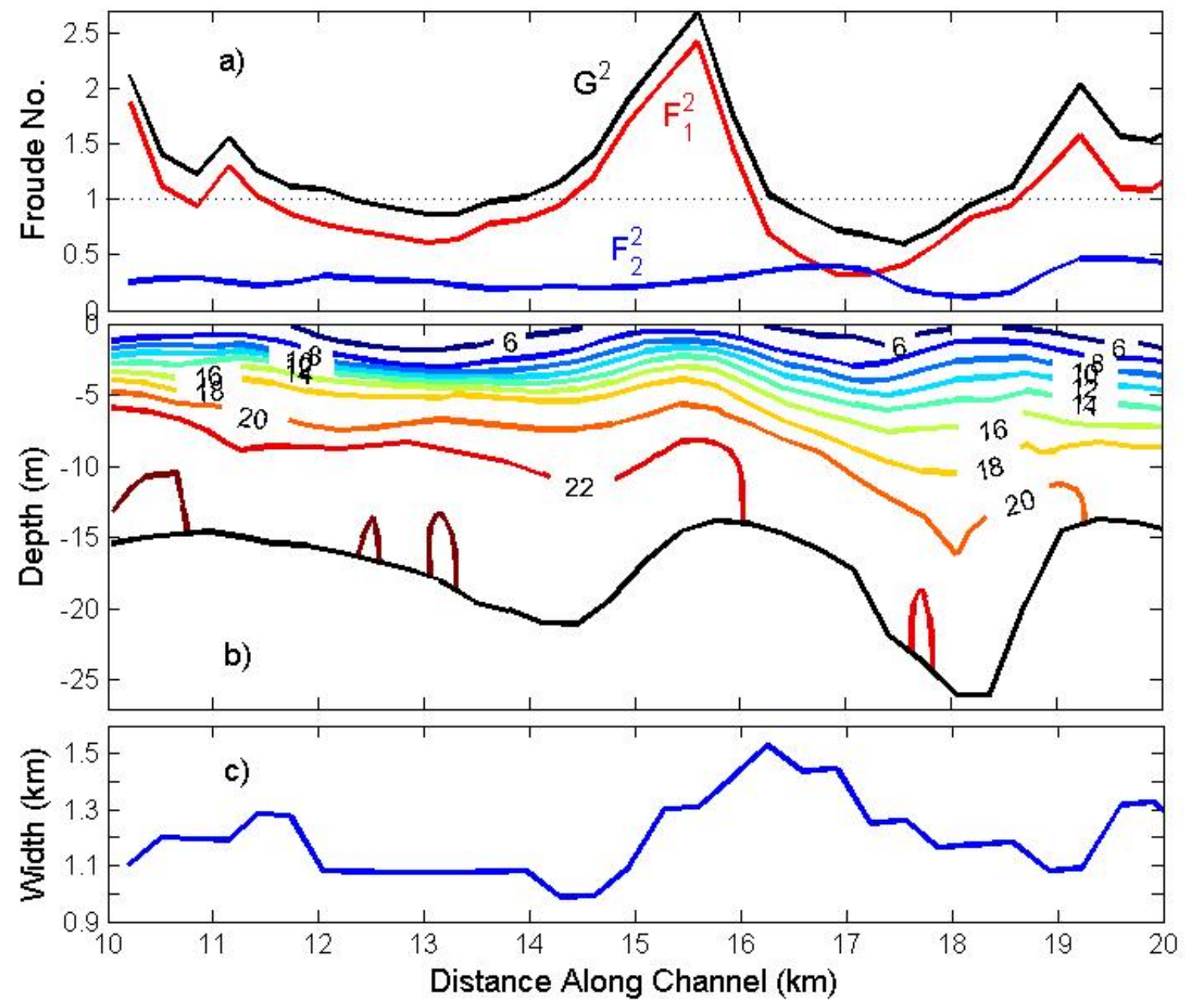

Figure 7. (a) Composite, $\mathrm{G}^{2}$, and layer Froude numbers, $\mathrm{F}_{1}{ }^{2}$ and $\mathrm{F}_{2}{ }^{2}$, (b) thalweg salinity, and (c) channel width, for flood, neap, and $\mathrm{Q}=600 \mathrm{~m}^{3} \mathrm{~s}^{-1}$. 
The layer Froude number in the upper layer was found to be larger than that in the lower layer at all but a few locations through the second half of flood and during all of ebb tide. This is due to the combination of higher upper layer velocities (during ebb) and consistently lower upper layer thickness (during both flood and ebb). As a consequence, variations in width have a significant influence on the structure and hydraulic state of the flow (Fig. 7c). In contrast, during early flood, the lower layer Froude numbers are larger than the upper, which indicates the importance of variations in channel depth. This is of particular interest as tidal asymmetries in salinity are generated during early flood. The influence of both width and depth variations are explored in section 4.2. 


\section{Discussion: Mechanisms of Tidal Salt Flux}

\subsection{Influence of Stratification}

Tidal asymmetry in stratification is the basic variable responsible for the tidal salt flux. Large tidal salt flux is associated with high stratification conditions: high river flow, neap tide, and the lower estuary. The tidal and estuarine salt fluxes are each highly correlated with stratification and thus with each other. This suggests that the mechanism causing the tidal salt flux is related to the stratification. One such mechanism is hydraulic response, which may lead to the observed tidal salt flux (as suggested by Geyer and Nepf [1996]).

\subsection{Hydraulic Adjustment of Stratification}

A hydraulic response to channel geometry modifies the salinity structure, generating tidal salt flux. Such a response is indicated by a thinning or thickening of salinity layers. A thinning of the upper layer is visible as an elevated interface level, sometimes referred to as 'heaving' [Geyer and Nepf, 1996]. This increases the crosssectionally averaged salinity. In contrast, a thickening of the upper layer appears as a deeper interface, with reduced cross-sectionally averaged salinity. The tidal asymmetry of the cross-sectionally averaged salinity generates the tidal salt flux. This asymmetry is generated by variations in Froude number, layer velocities, and the influence friction throughout the tidal cycle, as prescribed by two-layer hydraulic theory. 
Derived in Appendix 1, stratification is modified by changes in bottom elevation, $H$, channel width, $B$, surface elevation, $\eta$, flow state, and velocity in the following way:

$\frac{\partial h_{1}}{\partial x}\left(1-G^{2}\right)=F_{2}^{2}\left(\frac{\partial H}{\partial x}-\frac{\partial \eta}{\partial x}\right)+\frac{1}{B g^{\prime}} \frac{\partial B}{\partial x}\left(u_{1}^{2}-u_{2}^{2}\right)+\frac{c_{D}\left|u_{2}\right| u_{2}}{g^{\prime} h_{2}}-\frac{c_{i}|\Delta u|\left(u_{1}-u_{2}\right)}{g^{\prime}}\left(\frac{1}{h_{1}}+\frac{1}{h_{2}}\right)$

where $c_{i}$ is the interfacial drag and $c_{D}$ is the bottom drag. In this case, surface elevation and interfacial drag are small and can be neglected, reducing the equation to:

$$
\frac{\partial h_{1}}{\partial x}\left(1-G^{2}\right)=F_{2}^{2} \frac{\partial H}{\partial x}+\frac{1}{B g^{\prime}} \frac{\partial B}{\partial x}\left(u_{1}^{2}-u_{2}^{2}\right) \pm F_{2}^{2} c_{D}
$$

The ' + ' case is valid during flood, while the '-' case is valid during ebb.

Changes in bottom elevation in the presence of supercritical flows influence the upper layer thickness in the following ways: A shallowing of the channel $\left(\frac{\partial H}{\partial x}>0\right)$ contributes to a thinning of the upper layer, resulting in isopycnal heaving. In contrast, a deepening of the channel $\left(\frac{\partial H}{\partial x}<0\right)$ contributes to upper layer thickening, thus the depression of isopycnals. The opposite is true in the presence of subcritical flows.

The influence of changes in channel width on salinity structure is sensitive to the relative magnitudes of layer velocities. When the magnitude of the upper layer velocity is larger than that of the lower layer, a widening of the channel $\left(\frac{\partial B}{\partial x}>0\right)$ tends to thin the upper layer for supercritical flows and thicken it for subcritical flows. In contrast, a narrowing of the channel $\left(\frac{\partial B}{\partial x}<0\right)$ contributes to supercritical upper layer thickening and subcritical upper layer thinning. When the lower layer velocity becomes larger than the upper layer velocity during part of the flood tide, the upper layer thins when either supercritical flow passes through a region of expansion or subcritical flow passes through 
a region of narrowing. The upper layer is depressed (thickens) if supercritical flow passes through a region of channel narrowing or subcritical flow passes through a region of expansion.

The influence of friction on the salinity structure changes throughout the tidal cycle. In the presence of supercritical flow, friction acts to thin the upper layer during flood tide and thicken the upper layer during ebb. The opposite is true for subcritical flows. Thus, friction always contributes to positive tidal salt flux in the presence of supercritical flows, and negative tidal salt flux for subcritical flows.

The response of the salinity structure, to the triple influence of varying channel depth, changes in width, and friction, depends on the relative magnitude of each term in Equation 18. These magnitudes depend on the location within the channel (for variations in depth and width) and the time dependence of Froude numbers and layer velocities at those locations. The relative magnitudes of each term are described at two locations: the locations of large, positive tidal salt flux and large, negative tidal salt flux referred to in Section 3.2.

At the location of large, positive tidal salt flux, though all three terms influence the upper layer response, variations in channel depth dominate during flood and variations in channel width dominate during ebb. At maximum flood, supercritical flow over a shallowing bottom $\left(\frac{\partial H}{\partial x}>0\right)$ thins the upper layer $\left(\frac{\partial h_{1}}{\partial x}<0\right)$. At maximum ebb, supercritical flow and high upper layer velocities through a widening channel $\left(\frac{\partial B}{\partial x}>0\right)$ also thin the upper layer. Thinning during both flood and ebb is consistent with the modeled interface behavior at maximum flood and ebb (Fig. 8a). 


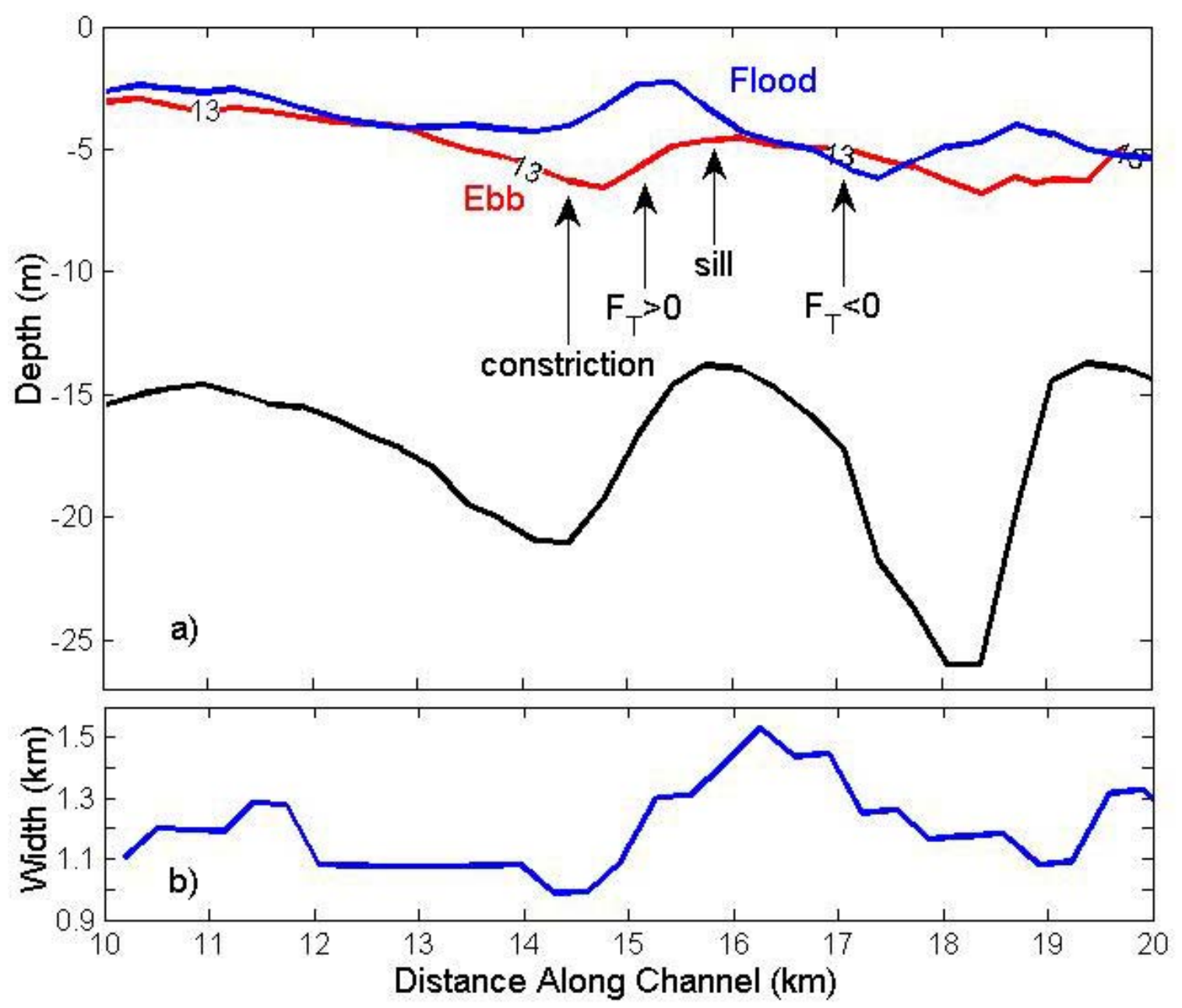

Figure 8. (a) The 13 psu isopycnal during flood and ebb, neap tide for $\mathrm{Q}=600 \mathrm{~m}^{3}$ $\mathrm{s}^{-1}$. Locations of interest are marked. (b) Channel width for comparison.

At the location of large, negative tidal salt flux all three terms are again important. The influence of variations in bottom elevation dominate during flood and both bottom elevation and channel width contribute strongly during ebb. At maximum flood, the barely supercritical flow through the deepening channel $\left(\frac{\partial H}{\partial x}<0\right)$ leads to upper layer thickening (Fig. 8a). At maximum ebb, highly supercritical flow through the deepening, narrowing channel $\left(\frac{\partial B}{\partial x}<0\right)$ continues to thicken the upper layer. However, the ebb 
response is weak due to the large composite Froude numbers at maximum ebb. This is consistent with the slope of the modeled 13 psu contour shown in Figure 8a.

These instantaneous hydraulic responses during maximum flood and maximum ebb are useful in demonstrating the applicability of the theory. However, the hydraulic response during late ebb and early flood is more relevant to the generation of asymmetry in tidal salinity, and thus tidal salt flux. Isohaline adjustment is largest during early flood and late ebb, when the composite Froude number is nearly critical. The lower layer Froude number, $F_{2}{ }^{2}$, is largest during early flood, which enhances the impact of variations in depth and friction. During ebb, $F_{2}{ }^{2}$, is reduced and the difference in layer velocities is maximal, which boosts the impact of channel width variations. The near critical composite Froude number between late flood and early ebb contributes little as both the difference in layer velocities and the magnitude of the lower layer Froude number are small. Thus, the net hydraulic influence at a cross-section can be approximated from its bottom slope during early flood and its variation in width during late ebb.

This steady, hydraulic theory does well to predict the instantaneous slope of the interface based on the triple influences of bottom elevation, channel width, and friction. However, it is the upper layer thickness itself, i.e. the depth of the interface, rather than the slope, which determines the cross-sectionally averaged salinity, and thus the tidal salt flux. The layer thickness at a particular location is strongly influenced by the slope of the upper layer just oceanward of it during flood, and just riverward during ebb. At the location of large, positive tidal salt flux, the thinning of the upper layer at cross-sections oceanward during flood and riverward during ebb contribute to the elevated interface 
during flood and depressed interface during ebb, the exact combination required for enhanced positive tidal salt flux. At the location of large, negative salt flux, the thickening of the upper layer, at oceanward cross-sections during flood and riverward during ebb, sets up a depressed interface during flood and an elevated interface during ebb, consistent with conditions required to generate negative tidal salt flux.

Hydraulic theory predicts most locations of positive and negative tidal salt flux based on the following specifications for channel geometry. A region of positive tidal salt flux is bounded on the ocean-side by a cross-section in which bottom elevation increases and the channel widens. On its river side, this region is bounded by a section of the channel which narrows as it deepens (Fig. 9). Combined with barely supercritical early-mid flood and subcritical late ebb flows, this geometry generates an elevated interface during flood and a depressed interface during ebb at all locations in the region with those geometrical characteristics. At these locations, the tidal cross-sectional salinity is high during flood and low during ebb, resulting in positive tidal salt flux.

A region of negative tidal salt flux, in contrast, is bounded by a cross-section of deepening, narrowing channel (ocean-side) and a cross-section of shallowing, widening channel (river-side). This results in the depression of the interface during flood and heaving during ebb, which generates the low salinity during flood and high salinity during ebb responsible for a negative tidal salt flux. 

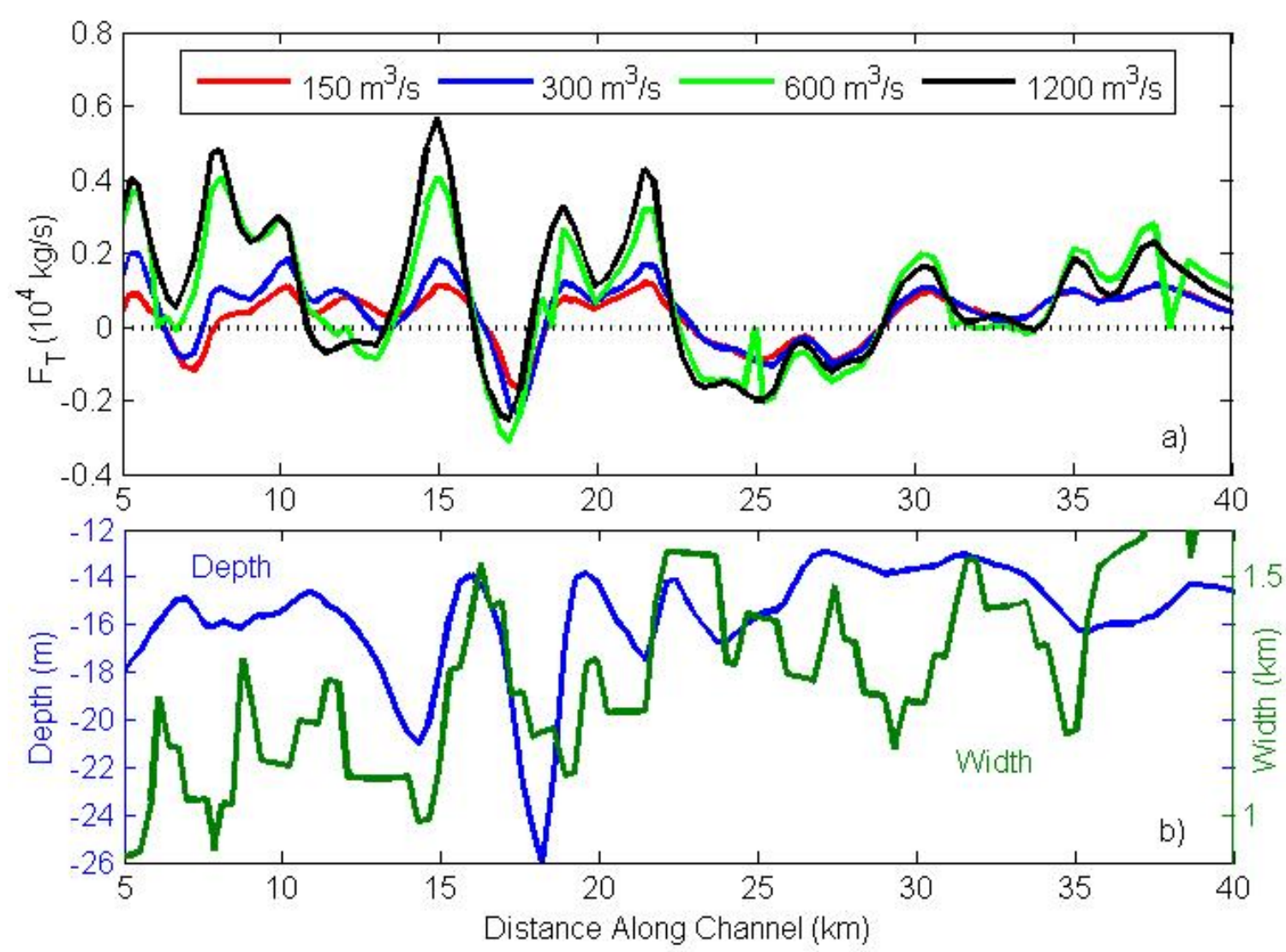

Figure 9. (a) Tidal salt flux at neap tide for $\mathrm{Q}=150 \mathrm{~m}^{3} \mathrm{~s}^{-1}$ (red), $300 \mathrm{~m}^{3} \mathrm{~s}^{-1}$ (blue), $600 \mathrm{~m}^{3} \mathrm{~s}^{-1}$ (green), and $1200 \mathrm{~m}^{3} \mathrm{~s}^{-1}$ (black). (b) Depth and width variations along the channel.

This two layer approach has several important limitations. It assumes a rectangular cross-section, uniform layer velocities, and ignores time dependence. To correct the first two limitations, future work may use the following formula, developed by Pratt [2008] for 2+ layer flows in which both the velocity and layer thicknesses vary in the transverse direction:

$$
G^{2}=\frac{1}{\frac{1}{B_{I}} \int_{0}^{B} \frac{g^{\prime} h_{1}}{v_{1}{ }^{2}} d x}+\frac{1}{\frac{1}{B_{I}} \int_{x_{L}}^{x_{R}} \frac{g^{\prime} h_{2}}{v_{2}{ }^{2}} d x}
$$

In the formula, $B_{I}$ is the interface width bounded on the left and right by $x_{L}$ and $x_{R}$, and $B$ is the width at the surface. However, while this formulation reduces the errors due to assuming a rectangular cross-section, it assumes a rigid lid, flat interface, neglects 
friction and ignores time dependence. Alternatively, the Taylor-Goldstein equation may be used to find limits on the wave speed, and thus determine the hydraulic state of the flow based on comparison with the current speed. However, this has its own limitations. In addition, this hydraulic understanding can not be applied to the head of salt region, where layer differences blur and time dependence becomes a major influence, i.e., regions in which the salt completely leaves at any point during the tidal cycle. Here the tidal salt flux is always positive due to the frictional phase lead of the bottom velocity which increases the cross-sectional salinity before quadrature with the cross sectional velocity. Regardless of topography, the salt increases with the inflowing tide and decreases on the ebb. 


\subsection{Summary and Conclusions}

The dependence of tidal salt flux on river flow, spring-neap tidal forcing, and bathymetric variations along the channel were explored using a 3D numerical model for the Hudson River estuary. Four river discharge conditions were used: $1200 \mathrm{~m}^{3} \mathrm{~s}^{-1}, 600$ $\mathrm{m}^{3} \mathrm{~s}^{-1}, 300 \mathrm{~m}^{3} \mathrm{~s}^{-1}$, and $150 \mathrm{~m}^{3} \mathrm{~s}^{-1}$. Tidal salt flux was found to be generally down-gradient and scale in magnitude with the river flow. Variability appears larger during neap tide, however, the magnitude has no clear spring-neap dependence. The diffusive fraction, $v$, indicates significant tidal salt flux relative to estuarine salt flux throughout the channel with dominance near the head of salt. High along channel variability of tidal salt flux included locations of strongly counter-gradient flux linked to topographic features.

The composite Froude number, $\mathrm{G}^{2}$, was calculated along the channel and indicated nearly ubiquitous supercritical flow for maximum flood and ebb during both neap and spring tides. Subcritical flow occurred during slack tides and at geographically locked locations during neap floods. Two-layer, frictional hydraulic theory was shown to predict the response of salinity structure to the combined flow state and channel geometry. The largest contributors to changes in layer thickness were caused by depth variations during flood and width variations during ebb. A general rule was given to determine along channel variability of tidal salt flux based on channel geometry, supporting the conclusion that tidal salt flux is generated by tidally asymmetric hydraulic distortions of the salinity field. Thus, modified by tides, river flow, and hydraulics, stratification is the key ingredient in tidal salt flux. 


\section{Bibliography}

Awaji, T.A., N. Imasato, and H. Kunishi, 1980: Tidal exchange through a strait: A numerical experiment using a simple model basin. J Phys Oceanogr 10, 1499-1508.

Bowden, K.F. 1965: Horizontal mixing in the sea due to a shearing current. J. Fluid Mech. 21, 83-95.

Bowen, M.M., 2000: Mechanisms and Variability of Salt Transport in Partially-Stratified Estuaries, Thesis.

Bowen, M.M., and W.R. Geyer, 2003: Salt transport and the time-dependent salt balance of a partially stratified estuary. J. Geophys. Res., 108 (C5), 3158, doi:10.1029/2001JC001231

Chant, R.J., and R.E. Wilson, 1997: Secondary circulation in a highly stratified estuary, $J$. Geophys. Res., 102(C10), 23,207-23,215.

Chant, R.J., Wilson, R.E., 2000: Internal hydraulics and mixing in a highly stratified estuary. J. Geophys Res., 105, 14,215-14,222.

Dronkers, J., and J. van de Kreeke, 1986: Experimental determination of salt intrusion mechanisms in the Volkerak estuary. Neth. J. Sea Res., 20, 1-19.

Fisher, H.B., 1972: Mass Transport mechanisms in partially mixed estuaries, J. Fluid Mech., 53(4), 671-687.

Fram, J., Martin, M., Stacey, M., 2007: Dispersive Fluxes between the Coastal Ocean and a Semienclosed Estuarine Basin. J Phys Oceanogr., 37, 1645-1660.

Geyer, W.R., R. Chant, and R. Houghton (2008), Tidal and spring-neap variations in horizontal dispersion in a partially mixed estuary, J Geophys Res, 113, C07023.

Geyer, W.R., Nepf, H., 1996: Tidal Pumping of Salt in a Moderately Stratified Estuary, Coastal and Estuarine Studies, 53, 213-226.

Geyer, W.R., Trowbridge, J.H., Bowen, M.M., 2000: The Dynamics of a Partially Mixed Estuary, J. Phys Oceanogr., 30, 2035-2048.

Hansen, D.V. and Rattray, M., 1965: Gravitational circulation in straits and estuaries. $J$. Mar. Res., 23, 104-122.

Hansen, D.V. and Rattray, M., 1966: New dimensions in estuary classification.

Limnology \& Oceanography, 11, 319-325. 
Hughes, F.W., Rattray, M., 1980: Salt flux and mixing in the Columbia River estuary. Estuarine and Coastal Mar. Sci., 10, 479-493.

Hunkins, K., 1981: Salt dispersion in the Hudson Estuary. J. Phys. Oceanogr., 11, 729738.

Imasato, N. 1983. What is tide-induced residual current? J Phys Oceanogr. 13, 13071317.

Larsen, L.H., 1977: Dispersion of a passive contaminant in oscillatory fluid flows. J., Phys. Oceanogr., 7, 928-931.

Lerczak, J.A., W.R. Geyer, and R.J. Chant, 2006: Mechanisms driving the timedependent salt flux in a partially stratified estuary. J. Phys. Oceanogr., 36, 2283-2298.

Lerczak, J.A., W.R. Geyer, and D.K. Ralston, 2009: The Temporal Response of the Length of a Partially Stratified Estuary to Changes in River Flow and Tidal Amplitude. $J$. Phys. Oceanogr., 39(4), 915-933.

Lewis, R.E., Lewis, J.O., 1983: The principal factors contributing to the flux of salt in a narrow, partially stratified estuary. Estuarine Coastal Mar. Sci., 16, 599-626.

Okubo, A. 1967: The effect of shear in an oscillatory current on horizontal diffusion from an instaneous source, Int. J. Oceanol. Limnol., 1(3), 194-204.

Okubo, A. 1973: Effect of shoreline irregularities on streamwise dispersion in estuaries and other embayments. Netherlands Journal of Sea Research 6: 213-224.

Ou , H.W., Dong, C.M., Chen, D., 2000: On the tide-induced property flux: can it be locally countergradient? J. Phys. Oceanogr., 30, 1472-1477.

Pratt, L. (2008). Critical conditions and composite Froude numbers for layered flow with transverse variations in velocity, J Fluid Mech, 605: 281-291.

Ralston, D.K., Stacey, M.T., 2005: Longitudinal dispersion and lateral circulation in the intertidal zone, J Geophys Res, 110, C07015.

Stacey, M.T., Ralston, D.K., 2005: The scaling and structure of the esuarine bottom boundary layer. J. Phys. Oceanogr., 35, 55-71.

Schilf, J.B. and J.C. Schonfeld. 1953. Theoretical considerations on the motion of salt and fresh water, p. 321-333. In Proceedings, Minnesota International Hydraulics Conference, Minneapolis, Minnesota. 
Scully, M.E., Geyer, W.R., Lerczak, J.A., 2009: The influence of lateral advection on the residual estuarine circulation: a numerical modeling study of the Hudson River estuary. $J$. Phys. Oceanogr., 39, 107-124.

Smith, R., 1976: Longitudinal dispersion of a buoyant contaminant in a shallow channel. J Fluid Mech, 78: 677-688.

Smith, R., 1977: Long-term dispersion of contaminants in small estuaries. J Fluid Mech, 82: 129-146.

Smith, R. 1982: Contaminant dispersion in oscillatory flows. J Fluid Mech, 114, 379-398.

Stenström, P., 2004: Hydraulics and mixing in the Hudson River estuary: A numerical model study of tidal variations during neap tide conditions. J Geophys. Res., 109, C04019

Stommel, H.M. and H.G. Farmer, 1953: Abrupt change in width in two-layer open chanel flow. J. Marine Res., 11, 205-214.

Uncles, R.J., Jordan, M.B., 1979: Residual fluxes of water and salt at two stations in the Severn Estuary. Estuarine and Coastal Marine Sci., 9, 287-302.

Warner, J.C., W.R. Geyer, and J.A. Lerczak, 2005: Numerical modeling of an estuary: A comprehensive skill assessment. J.Geophys. Res., 110, C05001, doi:10.1029/2004JC002691.

Zimmerman, J.T. F., 1986: The tidal whirlpool: A review of horizontal dispersion by tidal and residual currents. Netherlands Journal of Sea Research 20:133-154. 


\section{Appendix: \\ Hydraulic Theory}

Continuity Equations:

$u_{1} h_{1} B=Q_{1}=$ const

$u_{2} h_{2} B=Q_{2}=$ const

$h_{1}-\eta+\eta_{i}=$ const

$H+h_{2}=\eta_{i}$

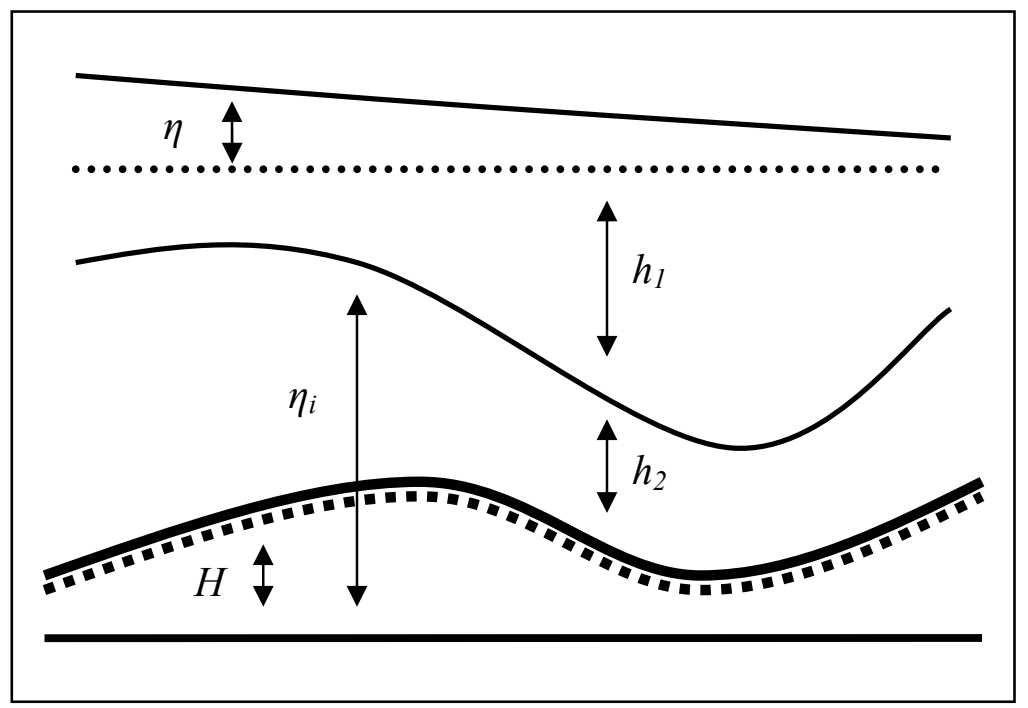

Momentum Equations:

$\frac{1}{2} \frac{\partial u_{1}^{2}}{\partial x}+g \frac{\partial \eta}{\partial x}=\frac{-c_{i}|\Delta u|\left(u_{1}-u_{2}\right)}{h_{1}}$
$\frac{1}{2} \frac{\partial u_{2}^{2}}{\partial x}+\frac{g \rho_{1}}{\rho_{2}} \frac{\partial \eta}{\partial x}+g^{\prime} \frac{\partial \eta_{i}}{\partial x}=\frac{c_{i}|\Delta u|\left(u_{1}-u_{2}\right)}{h_{2}}-\frac{c_{D}\left|u_{2}\right| u_{2}}{h_{2}}$

Subtracting the lower layer momentum equation from the upper and using the continuity equations gives:

$$
\begin{aligned}
\frac{-Q_{1}^{2}}{B^{2} h_{1}^{3}} \frac{\partial h_{1}}{\partial x}+\frac{Q_{1}^{2}}{B^{3} h_{1}^{2}} \frac{\partial B}{\partial x} & +\frac{-Q_{2}^{2}}{B^{2} h_{2}^{3}} \frac{\partial h_{2}}{\partial x}+\frac{Q_{2}^{2}}{B^{3} h_{2}^{2}} \frac{\partial B}{\partial x}+g^{\prime}\left(\frac{\partial \eta}{\partial x}-\frac{\partial \eta_{i}}{\partial x}\right) \\
& =\frac{-c_{i}|\Delta u|\left(u_{1}-u_{2}\right)}{g^{\prime}}\left(\frac{1}{h_{1}}+\frac{1}{h_{2}}\right)+\frac{c_{D}\left|u_{2}\right| u_{2}}{g^{\prime} h_{2}}
\end{aligned}
$$

Using the definition of layer Froude numbers, $G^{2}=F_{1}^{2}+F_{2}^{2}=\frac{u_{1}^{2}}{g^{\prime} h_{1}}+\frac{u_{2}^{2}}{g^{\prime} h_{2}}$, this equation can be rewritten as follows:

$\frac{\partial h_{1}}{\partial x}\left(1-G^{2}\right)+F_{2}^{2}\left(\frac{\partial \eta}{\partial x}-\frac{\partial H}{\partial x}\right)+\frac{1}{B} \frac{\partial B}{\partial x}\left(F_{2}^{2} h_{2}-F_{1}^{2} h_{1}\right)=\frac{-c_{i}|\Delta u|\left(u_{1}-u_{2}\right)}{g^{\prime}}\left(\frac{1}{h_{1}}+\frac{1}{h_{2}}\right)+\frac{c_{D}\left|u_{2}\right| u_{2}}{g^{\prime} h_{2}}$ which becomes:

$\frac{\partial h_{1}}{\partial x}\left(1-G^{2}\right)=F_{2}^{2}\left(\frac{\partial H}{\partial x}-\frac{\partial \eta}{\partial x}\right)+\frac{1}{B g^{\prime}} \frac{\partial B}{\partial x}\left(u_{1}^{2}-u_{2}^{2}\right)+\frac{c_{D}\left|u_{2}\right| u_{2}}{g^{\prime} h_{2}}-\frac{c_{i}|\Delta u|\left(u_{1}-u_{2}\right)}{g^{\prime}}\left(\frac{1}{h_{1}}+\frac{1}{h_{2}}\right)$ 